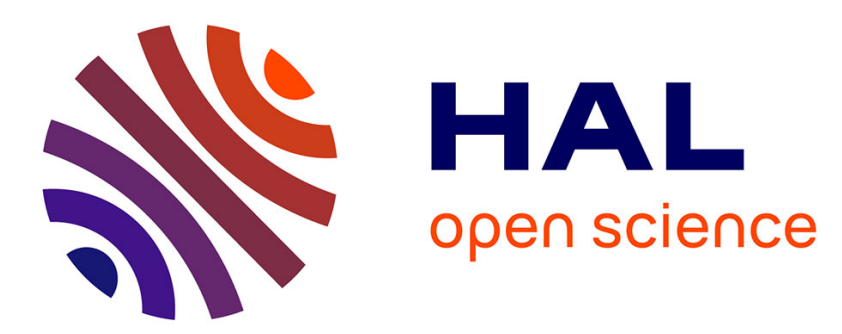

\title{
Improved unconventional reservoir characterization using multi-azimuth stratigraphic inversion, case study on the Fort Worth Basin.
}

\author{
Mathilde Adelinet, A. Barnoud, Vincent Clochard, Patrice Ricarte
}

\section{- To cite this version:}

Mathilde Adelinet, A. Barnoud, Vincent Clochard, Patrice Ricarte. Improved unconventional reservoir characterization using multi-azimuth stratigraphic inversion, case study on the Fort Worth Basin.. Journal of Unconventional Oil and Gas Resources, 2013, pp.xxx-xxx. 10.1016/j.juogr.2013.10.001 . hal-00907763

\section{HAL Id: hal-00907763 \\ https://hal-ifp.archives-ouvertes.fr/hal-00907763}

Submitted on 21 Nov 2013

HAL is a multi-disciplinary open access archive for the deposit and dissemination of scientific research documents, whether they are published or not. The documents may come from teaching and research institutions in France or abroad, or from public or private research centers.
L'archive ouverte pluridisciplinaire HAL, est destinée au dépôt et à la diffusion de documents scientifiques de niveau recherche, publiés ou non, émanant des établissements d'enseignement et de recherche français ou étrangers, des laboratoires publics ou privés. 


\title{
Improved unconventional reservoir characterization using multi azimuth stratigraphic inversion, case study on the Fort Worth Basin
}

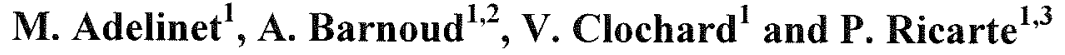 \\ ${ }^{1}$ IFP Énergies nouvelles, 1 et 4 avenue Bois-Préau, 92852 Rueil-Malmaison, France. \\ ${ }^{2}$ Now at ISTerre, CNRS (UMR 5275), Université Joseph Fourier, Grenoble, France. \\ ${ }^{3}$ Now at CGG-Veritas, Pau, France.
}

\begin{abstract}
The development of the exploration and exploitation of unconventional hydrocarbons requires innovative skills to allow a better characterization of natural fracture networks and fracability of the rocks at depth. Within this context, we bring into focus a multi-azimuth inversion methodology to give clues about the "sweet spots" characterization through the Barnett Shales formation. To achieve our goal we used an isotropic model-based stratigraphic seismic inversion, considering a series of azimuthal sectors to build partial seismic stacks required as input of the workflow. The initial seismic survey was recorded over a surface of approximately 100 square miles to image the Barnett Shales formation, of about 150 feet thickness only and localized in a transition zone between the oil and gas window. A preliminary processing task was to define limits of azimuthal and incidence angle sectors to build several multi-azimuth post-stack and pre-stack seismic dataset. Two exploration wells with a set of log data are available in the interest area helping in the model a priori building and in the well-to-seismic calibration, both crucial steps to apply the inversion workflow. We first perform full post-stack and pre-stack usual inversion to help in finding sets of best inversion parameters, then we do the multi-azimuth post-stack and pre-stack inversion workflow using the same previous sets of parameters for each azimuthal sector. Consequently a series of acoustic impedance, $P$ - and $S$-wave elastic impedance cubes are computed for each azimuthal sector. Another aspect of the study is the quantification of azimuthal variations using an ellipse fitting algorithm giving, for each bin of the interest volume, the ratio (between major and minor axes) and tilt (i.e. azimuth from the East) of the ellipse. Results showed up to $10 \%$ of anisotropy for impedances in the Barnett Shales. We go a step further computing geomechanical features like Poisson's ratio and brittleness coefficient within the Barnett Shales and we quantified their azimuthal variations. Some areas present lower
\end{abstract}


Poisson's ratio and higher brittleness than other parts. It may suggest that the latter are "sweet spots" that could be more easily stimulated by induced fracturing.

\section{Keywords}

stratigraphic inversion; Barnett Shales; multi-azimuth fold; Poisson's ratio; brittleness

\section{Introduction}

The Barnett Shales belong to the Bend arch - Fort Worth Basin area which is a major mature petroleum province located in north-central Texas. This basin was exploited for its conventional resources throughout the twentieth century. Since 2000, the Mississippian Barnett Shales are recognized as a giant continuous gas reservoir. In 2010, the Barnett field production was about $40 \%$ of the total annual shale gas production in USA [EIA data, 2010]. To gain a better understanding of the reservoir behaviour during production, and by this way increasing hydrocarbon recovery, more information about the reservoir properties are essential.

As gas or oil shales formations act both as the source and the reservoir, fluid is generally diffuse within the rock and do not allow to be visible by standard seismic studies. That is why we need new geophysical approaches to better characterize this type of reservoir [Rich \& Ammerman, 2010]. In the last decade most a lot of studies deal with passive seismic surveys and induced microseismicity characterization [Rutledge \& Phillips, 2003; Maxwell et al., 2006; Shapiro \& Dinske, 2009; Eisner et al., 2010]. However active seismic methods also offer indirect ways to provide information on unconventional reservoirs through particular studies, such as waves attenuation [Dvorkin \& Uder, 2004; Carcione \& Piccoti, 2006], facies analysis [Roy \& Marfurt., 2011] or azimuthal variation of attributes [Zhang et al., 2010; Thompson et al., 2010]. In such complex geological context, there is a renewed interest in relating seismic data to geomechanical properties in gas shales [Gray et al., 2012].

One challenging issue to better produce an unconventional reservoir is to generate drainage pathways and create connected fractures networks. Hydraulic stimulations are employed by injecting large volume of water within the reservoir. Induced fracture networks develop in accordance with the stress orientations at the macroscale. However, at the microscale, it is not so obvious. Refunjol et al. [2012] show that microseismic event locations are correlated to 
areas of low seismic impedance values. Such a correlation between active seismic attributes and microstructure leads us to go further.

We applied a full multi-azimuth pre-stack inversion methodology to an exploration area of the Barnett Shales from the Southern part of the Fort Worth Basin. Then quantification of azimuthal variations of rock physics attributes at the seismic scale, gives clues about "sweet spots" distribution thanks to horizon maps extracted from inverted cubes.

\section{Geological background}

The Barnett Shales reservoir forms the primary source rock for hydrocarbon production in the Fort Worth Basin area [Pollastro et al. 2007]. Figure 1 illustrates the geological context of the Barnett Shale formation. The Fort Worth basin is located between two structural fronts: the Bend arch in the West and the Ouachita thrust fault in the East. In the North an other structural limit is present, the Muenster Arch which is the Northern ending of the Ouachita front. The basin is delimited in the South by the Llano uplift. The total extent for the Barnett is estimated by USGS to 6,458 square miles.

Our investigated area is the Mississipian Barnett Shales deposited above the Ellenburger group forming the Ordovician unconformity and is overlained by the Marble Falls limestone dated from the Pennsylvanian. At the location of the present study, the Barnett Shales are not divided into an upper and a lower part as it is across most of the basin: the Barnett unit is continuous from the bottom of the Marble Falls to the top of the Ellenburger. According to $\log$ data, the Barnett Shales are lying at depth around $1100 \mathrm{~m}$ (between $4070 \mathrm{ft}$ at well 1 and $4280 \mathrm{ft}$ at well 2, see Figure 2). Its thickness is variable between 30 and $45 \mathrm{~m}(110-170 \mathrm{ft})$. From a petrographical point of view, the Barnett is a calcite-rich shale with a high biogenic silica content. It is a high-thermal-maturity system which generates gas or oil according to the depth reached across the geological ages.

\section{Seismic data}

Two sets of seismic data were acquired in 2005 and 2006 in the Fort Worth Basin. As presented on Figure 3, the combined dataset covers about 90 square miles. The study area was 
restricted to a limited zone ( 316 inlines by 311 crosslines, corresponding to about 26 square miles) including the well 1 because seismic data were only migrated in this area but the overall methodology could easily be generalized to the whole area for further investigations. From the initial seismic Common Mid-Points (CMP) migrated gathers, we build a multiazimuth post-stack seismic dataset by stacking seismic traces according to 6 azimuthal sectors. They are defined with a constant range every $30^{\circ}: 0-30^{\circ}, 30-60^{\circ}, 60-90^{\circ}, 90-120^{\circ}$, $120-150^{\circ}$ and $150-180^{\circ}$ (angles from the East). Consequently 6 post-stack seismic cubes are available. Then, a multi-azimuth pre-stack seismic dataset is built, stacking traces for each azimuthal sector taking into account the incidence angle of the seismic rays: $1-15^{\circ}, 16-25^{\circ}$ and $26-45^{\circ}$, roughly corresponding to NEAR, MID and FAR offsets respectively (Figure 4). Indeed, for a given offset, a wide incidence angle range is observed. So, seismic data are sorted according to incidence angles rather than offsets. We choose limit angles according to an equal distribution of traces into a bin. Finally 18 pre-stack azimuthal seismic cubes are available ( 6 azimuthal by 3 incidence sectors). In both cases, we stack together all the azimuthal sectors to build the post-stack ( 1 available seismic cube) and the pre-stack seismic datasets ( 3 available seismic cubes).

The challenging part of this work is first to show the feasibility of the multi-azimuth stratigraphic inversion workflow with pre-stack seismic data. Secondly it is to quantify azimuthal variations of inverted elastic parameters, and of other rock physics attributes to characterize the Barnett Shales.

\section{Multi-azimuth stratigraphic inversion workflow}

The sensu-stricto stratigraphic inversion workflow is divided into three main steps [Delépine et al., 2010]. First, the migrated post- and pre-stack seismic data (in fact, full and partial azimuthal stacks) have to be calibrated with well log data at reservoir scale [Lucet et al., 2000]. The main issue of this step is to find, for each azimuthal partial or full stack an optimal wavelet satisfying the correlation between surface seismic datasets and synthetic traces computed at the wells. The synthetic trace at the well is obtained by a 1D-convolution of the Two Way Time (TWT) reflectivity by the estimated wavelet (Figure 5). To do this, we first need to convert in the TWT domain, filter and resample the reflectivity compuled from the Aki-Richards approximation [Aki \& Richards, 1980] using the density, compressional and 
shear sonic logs (recorded in the depth domain), because our inversion workflow is working in the time domain. Secondly, an a priori model is generated, parameterized by acoustic impedance to invert post-stack seismic data and parameterized by $P$ - and $S$-wave elastic impedances and density to invert pre-stack seismic data. This step requires interpreted horizons derived from the full stack of seismic data associated with the delimitations of the major geological units and their modes of deposition. In the investigated area, two main horizons are defined (Figures 2 and 3b): the top of the Marble Falls (around $600 \mathrm{~ms}$ in coming figures) and the bottom of the Barnett Shales formation (around $680 \mathrm{~ms}$ ). Finally, the third step consists in performing sequential and independent isotropic model-based post-stack and pre-stack inversions for each azimuthal sectors. In the following, the presented multi-azimuth inversion methodology uses six azimuthal sectors.

The final stage of the multi-azimuth stratigraphic inversion workflow is to quantify the $3 \mathrm{D}$ azimuthal variations of elastic and physical parameters. To achieve this goal we use an explicit ellipse fitting algorithm which initial equations are derived from Dey et al. [1999]. To define such an ellipse, three pieces of information must be known: the lengths of the short and long axis and the orientation of the ellipse $\theta$. For a given bin of the inverted target volume the fitting uses 12 values, noted $V, 6$ azimuthal values on $0-180^{\circ}$ (corresponding to the 6 defined azimuthal sectors) and their projections on $180-360^{\circ}$ (Figure 6). Let $x(i)$ and $y(i)$ be the projections of $V(i)$ onto a Cartesian coordinate system, with $i$ varying from 1 to 12 . The coordinates $(\bar{x}, \bar{y})$ of the mean centre are expressed according:

$$
\bar{x}=\frac{\sum_{i} x(i)}{12} \text { and } \bar{y}=\frac{\sum_{i} y(i)}{12}
$$

Then we translate the coordinates of the data by subtracting the mean for each original coordinate:

$$
x^{\prime}=x-\bar{x} \text { and } y^{\prime}=y-\bar{y}
$$

We calculate the tangent of the orientation angle of the ellipse by:

$$
\tan \theta=\frac{\sum_{i} x^{\prime 2}-\sum_{i} y^{\prime 2}+\sqrt{\left(\sum_{i} x^{\prime 2}-\sum_{i} y^{\prime 2}\right)^{2}+4\left(\sum_{i} x^{\prime} y^{\prime}\right)^{2}}}{2 \sum x^{\prime} y^{\prime}}
$$

Finally the short and long axis, respectively denoted $a$ and $b$, are expressed as the standard deviation along the $\mathrm{x}$-axis and the $\mathrm{y}$-axis of the ellipse: 


$$
a=\sqrt{\frac{\left(x^{\prime} \cos \theta-y^{\prime} \sin \theta\right)^{2}}{12}} \text { and } b=\sqrt{\frac{\left(x^{\prime} \cos \theta+y^{\prime} \sin \theta\right)^{2}}{12}}
$$

In the following section we would only present the results obtained on the ratio $b / a$ which is always higher than 1 . The difference between $b / a$ and 1 corresponds to the part of anisotropy within the impedance data set.

One has to keep in mind that these formulas can be used with any kind of parameters as long as azimuthal cubes are available: seismic attributes (e.g. amplitudes), inverted parameters such as acoustic and elastic impedances and also any derived parameters like Poisson's ratio, Young modulus or brittleness.

\section{Inversion results}

\subsection{Inversion QCs at well}

In a first attempt, we perform usual post-stack inversion to see the behaviour of the optimizing process in the simplest case. It is also useful to define the best set of inversion acoustic parameters (summarized in the Table 1). In this case we have to keep in mind only the acoustic impedance $(A I)$ could be inverted. In a second attempt, we perform a pre-stack inversion to go further in the complexity of the inversion process. We keep the previously defined set of parameters to invert the $P$-wave elastic impedance $(I P)$, then we define a specific set of parameters for $S$-wave elastic impedance (IS) and also the density $\rho$ (all summarized in the Table 2). In the pre-stack case with three incidence angle classes we have to keep in mind that it is now possible to invert three elastic parameters $(I P, I S, \rho)$. One can also notice that we are able to define physical constraints on Poisson's ratio and they have been chosen large enough to have a good inversion QC at Well (Figure 7). The overall trend of inverted $A I, I P$, and filtered logs are the same and show the differences with the a priori model. With these series of parameters the residues are randomly distributed with weak amplitudes (Figure 8) compared to the initial seismic data.

\subsection{From multi-azimuth post-stack data}

We display vertical sections, inlines through the well, extracted from inverted acoustic impedance $(A I)$ computed by inversion of post-stack seismic data (upper row of Figure 9 called "ALL") and inversion of two azimuthal sector stacks (Figure 9, middle row called 
"15" and bottom row called "135"). Comparing these three sections we can already see some azimuthal $A I$ variations (see black arrows). A main normal fault is visible in the Northwestern part of the area (dashed line on Figure 9 and coming figures). Middle and right columns of the Figure 9 show horizon maps through these $A I$ cubes cutting the Marble falls (orange colours) and the Barnett Shales (green colours). From a qualitative point of view differences are weak but already visible from azimuth $15^{\circ}$ compare to azimuth $135^{\circ}$. In the following interpretative sections we will show how to quantify these azimuthal variations. The horizon map from the post-stack data looks smoother laterally because the full stack tends to smooth heterogeneities. On the other hand impedance contrasts are enhanced.

We apply the post-stack inversion on seismic data, stacked for each azimuthal sector, and using the same set of parameters defined in the Table 1. As a result the sequential process produces as many acoustic impedance cubes as azimuthal sectors, i.e. 6 in our case study. Then in order to quantify azimuthal variations of $A I$, a robust explicit formulas of ellipse fitting algorithm, previously described from [Dey et al., 1999], has been applied successively for each bin of the interest area. Considering the value in the same bin through the series of six $A I$ cubes, the ellipse fitting algorithm works effectively with 12 values of $A I$ for symmetrical reasons (Figure 6). The whole process is able to compute cubes of major semiaxis, minor semi-axis and tilt of ellipse. We define the anisotropic ratio as the ratio between the major and the minor semi-axis. It corresponds to a value larger than 1 (isotropic case where all attributes remain constant with azimuth). Anisotropic ratios of IP inferred from post-stack inversions are displayed for the inline through the well (top of Figure 10) and different horizon maps through the three lithologies (the Barnett Shales and two carbonates with Marble Falls and the Ellenburger). Another study shows that azimuthal variation of acoustic impedance is more sensitive to large scale fracture detection [Al-Kandari et al., 2009]. Indeed, the highest ratio values are more distributed along the main fault (dashed line on Figure 10). In their study a lot of wells were available allowing a precise characterization of the fractures linked with quantification of azimuthal acoustic impedance variations. With our case study, the highest values are more present in the carbonates (bottom of Figure 10, left and right part), rather than in the shales (middle part). Note a ratio equal to one means there is no azimuthal variation of the inverted parameter, in other words seismic amplitudes are not affected by wave propagation in an isotropic geological unit at seismic scale. 


\subsection{From full-azimuth pre-stack data}

The next step of our study is to apply the pre-stack inversion to provide $P$ - and $S$-wave impedances (IP and IS), and density ( $\rho$ ). These inversion parameters are used to compute two rock physics attributes, the Poisson's ratio $v$ and the Young modulus $E$ (respectively Figures 11 and 12). The following equations relate the parameters IP, IS, $\rho, v$ and $E$ :

$$
v=\frac{1}{2} \frac{\left(\frac{I P}{I S}\right)^{2}-2}{\left(\frac{I P}{I S}\right)^{2}-1} \quad \text { and } \quad E=\frac{2 I S^{2}(1-v)}{\rho}
$$

From a set of horizon maps cutting different kinds of lithologies we distinguish two types of carbonates, Marble Falls and Ellenburger, and the Barnett Shales. At this stage we could observe different trends of values according to these lithologies. The Young modulus is quite constant into the same layer and is distinctive for the three formations: about $60 \mathrm{GPa}$ in the Marble Falls, $35 \mathrm{GPa}$ in Barnett Shales and around $90 \mathrm{GPa}$ for the Ellenburger. The last one presents more lateral variation than others. Poisson's ratio is not so constant into the same lithology. Indeed, for the Ellenburger, the strongest values are located on the other side of the main fault (dashed line on Figures 11 and 12). It is probably the evidence of a large fault throw in these limestones. Also it is interesting to note there is no direct link of the distributed values from the deeper Ellenburger to the overlaying Barnett Shales horizon maps. The faulted aspect of the Ellenburger (West-South to North-East trend) has been widely attenuated in the above Barnett Shales. Into Marble Falls and Barnett Shales, we observed a similar trend for Poisson's ratio: lower values in the Northern part of the area and stronger values in the Southern part. As seen above, the Young modulus does not present lateral variations. Moreover, the calculation of Young modulus requires the density data. Among the prestack output parameters, density is the worst constrained and fitted. Consequently we would focus the advanced analysis on the Poisson's ratio attribute. The Ellenburger formation presents a global Poisson's ratio lower than the Marble Falls one (larger green areas on Figure 11). Now, $\log$ data (in particular PhotoElectric absorption Factor log) show that the carbonates from the top of the Ellenburger contain mostly dolomite. Yet, it is known that Poisson's ratio in dolomite is lower than in calcite [e.g. Gercek, 2007]; thus our inversion results are in agreement with previous studies. From a geological point of view, the dolomitization of Ellenburger limestones is probably due to regional periods of karstification [Kupecz \& Land, 
1991] but also to late diagenetic deep-burial processes [Amthor \& Friedman, 1992]. Within the Barnett Shales, Poisson's ratio is distributed into two main values: around 0.3 in the large south-western part of the study area and around 0.2 in the northern strip. Lowest values could be due to lateral facies variation, with a higher calcite content into the shales for instance.

The brittleness attribute $(\mathrm{Br})$ is also computed from inversion results (Figure 13). However we used the formulation described in [Rickman et al., 2008] which is only valid in shales due to restrictive assumption:

$$
B r=\frac{1}{2}\left(\frac{v-0.4}{v_{0}-0.4}\right)+100\left(\frac{E-10}{E_{0}-10}\right)
$$

where $E_{0}$ and $v_{0}$ are reference values for Young modulus and Poisson's ratio, respectively equal to 0.15 and $80 \mathrm{GPa}$ in [Rickman et al., 2008]. If the Young modulus is expressed in $\mathrm{GPa}$, the brittleness is a percentage. Two main areas are enhanced on Figure 13, in the northern part with values between around [30-40\%] and in the southern part with values between $[50-70 \%]$ in correlation with what is observed on the Poisson's ratio analysis. Finally the pre-stack inversion is useful to compute complementary rock physics attributes from $P$ and $S$-wave impedances and it is a first step towards "sweet spots" characterization. Let us see how to go further considering multi-azimuth inversion of seismic datasets.

\subsection{From multi-azimuth pre-stack data}

We go one step further with multi-azimuth pre-stack inversion. We apply the ellipse fitting on both elastic parameters $P$ - and $S$-wave elastic impedances (Figure 14). With the pre-stack inversion methodology, we can see stronger values of the ratio distributed on the $S$-wave impedances. It is especially visible on the horizon maps from the Marble Falls (Figure 14 left column) and the Barnett Shales (Figure 14 middle column). We remind the set of inversion parameters is exactly the same from an azimuthal sector to another, but we have to keep in mind that only $P P$-wavefield is inverted. Nevertheless the pre-stack inversion with three angle classes is able to invert an elastic model parameterized by $P$ - and $S$-wave impedances. At this stage, we can only conclude the optimization process is finding the best isotropic elastic model to explain azimuthal partial stacks and it seems necessary to have more azimuthal variations of $S$-wave impedance rather than $P$-wave impedances.

The Poisson's ratio, which depends on the IP/IS ratio, provides much tighter constraints on the geological layers than either the compressional or the shear impedance alone. Consequently, we also apply the ellipse fitting on the Poisson's ratio inferred from prestack impedances IP 
and IS (Figure 15). Poisson's ratio appears to be much more anisotropic in the carbonates layer than in the Barnett Shales. It is the same observation that the one made on the post-stack ellipse fitting (Figure 10). This azimuthal variation of the Poisson's ratio in fractured rocks such as carbonates could be due to different states of opening in fractures families [Walsh, 1965].

\section{Discussion}

Our different results obtained with multi azimuth seismic data first requires us first to interpret the meaning of changes in Poisson's ratio. Indeed values of this ratio between 0.2 and 0.4 can have a variety of implications. If we put aside a strong change in the compositional of the layers, such as what happens in crustal environments [Owens \& Zandt, 1997], we can provide two main reasons for explaining Poisson's ratio variations. Firstly, the fluid content notably affects the wave fields within sedimentary basins. For instance an increase in gas content could sharply decrease the Poisson's ratio specially in the shales [Barree, 2009]. Secondly, the presence of open fractures in geological layers induces variations in wave fields and an azimuthal lateral variation is specially observed [Sayers \& Rickett, 1997; Perez et al., 1999]. In our case study, both causes could be involved. Indeed, the oil-gas front is close from our study play (Figure 1) and a major fault crosses the investigated area. However, the influence of fractures should prevailed, specially to explain the difference observed between carbonate layers and the Barnett Shales in terms of Poisson's ratio anisotropy (Figure 15). The proximity of the major fault probably generates a family of diffuse fractures through the carbonates and shales in a different way. Of course, they are not directly visible in the seismic frequency band pass but revealed by the quantification of azimuthal variations of impedances and geomechanical parameters. We also did synthetic studies to evaluate the ability of our multi-azimuth inversion workflow to retrieve the characteristics of a fracture family from inverted elastic $P$ - and $S$-wave impedances [Adelinet et al., 2012]. The multi-azimuth anisotropic seismic dataset was modelled using an effective medium with diffuse fractures characterized by their densities and orientations. We applied the same multi-azimuth pre-stack inversion workflow described previously, assuming that azimuthal $P$-wave impedance variation is weak with an identical wavelet for all azimuthal sector. One of the conclusions of the synthetic study is the effective ability of the multiazimuth inversion workflow in retrieving the characteristics of a fracture family (ratio and tilt of the fitted ellipses). So it seems reasonable to us to apply the same workflow for our real 
case study, since the ratios computed from $P$-wave impedances are weak (top of Figure 14) compare to ratios from $S$-wave impedance (bottom of Figure 14). Nevertheless our synthetic study provides good correlation between ellipse tilts and crack orientations as long as there is no more than two crack families. In the present real case, the number of main fracture families should be higher than 2 . Consequently we cannot interpret properly the tilts obtained after the fitting process as being the main direction of fracturation. However, the anisotropy ratio obtained on the Poisson's ratio could be interpreted as a gradient of fracture intensity into the Marble Falls / Ellenburger carbonates and the Barnett shales.

\section{Conclusions}

We have presented a multi-azimuth inversion methodology, performing successful multiazimuth post-stack and pre-stack inversion workflow using 6 azimuthal sectors. One of the difficulty was to handle 18 seismic cubes ( 6 azimuthal by 3 incidence sectors), especially for the well-to-seismic calibration step. From the inverted elastic parameters we have succeeded in quantifying azimuthal variations of geomechanical parameters such as Poisson's ratio and brittleness. One has to keep in mind that it is not possible with only a multi-azimuth poststack inversion alone because only acoustic impedance is retrieved. Unfortunately our interest area was only investigated for exploration purposes and no more wells were drilled so that no production data are available, limiting further interpretation.

The crucial inverted parameters are the $S$-wave impedance and the density [Lebrun et al., 2001]. They could be improved if we were able to record multi-component seismic data and extract PS-wavefield [Shatilo et al., 2012]. They could also be much better resolved with more sophisticated acquisition techniques with $S$ sources [De Vault et al., 2007] and $S S$ wavefield extraction. We hope the unconventional reservoir exploration and exploitation will promote multi-azimuth and multi-component seismic surveys to better predict "sweet spots" locations.

\section{Acknowledgements}

The authors would like to thank the European GASH project for providing them with seismic and log data. They also thank Isabelle Moretti (now at GDF Suez), Sébastien Rohais and 
William Sassi from IFP Energies nouvelles to shed us light on the geological characteristics of the Fort Worth Basin.

\section{Bibliography}

Adelinet, M., C. Dorbath, M. Le Ravalec, J. Fortin and Y. Guéguen [2011] Deriving microstructure and fluid state within the Icelandic crust from the inversion of tomography data. Geophys. Res. Letters, 38, L03305.

Adelinet, M., Clochard, V., Barthélémy, J. F., \& Chérel, L. [2012] Determination of Crack Orientation in a Fractured Reservoir from Effective Medium Modelling and Multi-azimuth Inversion. In 74th EAGE Conference \& Exhibition.

Aibaidula, A. and G. McMechan [2009] Inversion and interpretation of a 3D seismic data set from the Ouachita mountains, Oklahoma. Geophysics, 74, 2, B37-B45.

Aki, K. \& Richards, P. G. [1980] Quantitative Seismology, second edition. University Science Books, Sausalito, California.

Al-Kandari, A., Kumar, R., Convert, P., Ortet, S., \& Lecante, G. L. [2009]. Fracture characterization using seismic data in a West Kuwait field. In 2009 SEG Annual Meeting.

Amthor, J. E., \& Friedman, G. M. [1992] Early-to late-diagenetic dolomitization of platform carbonates: Lower Ordovician Ellenburger Group, Permian Basin, west Texas. Journal of Sedimentary Research, 62(1).

Barree, R., Gilbert, J., \& Conway, M. [2009] Stress and rock property profiling for unconventional reservoir stimulation. In SPE Hydraulic Fracturing Technology Conference.

Carcione, J.M. and S. Picotti [2006] P-wave seismic attenuation by slow-wave diffusion: effects of inhomogeneous rock properties. Geophysics, 71, 3, 1-8. 
Delépine, N., V. Clochard, K. Labat, and P. Ricarte [2011] Post-stack stratigraphic inversion workflow applied to carbon dioxide storage: application to the saline aquifer of Sleipner field. Geophysical Prospecting, 59, 1, 132-144.

DeVault, B., Tonellot, T., Macé, D., Ker, S., \& Pichard, M. [2007] Prestack 9-C Joint Inversion For Stratigraphic Prediction In the Williston Basin. In 2007 SEG Annual Meeting.

Dey, A. K., C. Rai and C. Sondergeld [1999] Quantifying uncertainties in AVO forward modelling, SPE Expanded abstracts.

Dvorkin, J. and R. Uden [2004] Seismic wave attenuation in a methane hydrate reservoir. TLE, 23, 8, 30-32.

EIA [2010] Annual energy outlook 2010. DOE/EIA-0383(2010). Energy Information Agency, U.S. Department of Energy.

Eisner, L., B.J. Hulsey, P. Duncan, D. Jurick, H. Werner and W. Keller [2010] Comparison of surface and borehole locations of induced seismicity. Geophysical Prospecting, 58, 5, $1365-2478$

Gale, J.F.W., Reed, R.M. and J. Holder [2007] Natural fractures in the Barnett Shale and their importance for hydraulic fracture treatment. AAPG Bulletin, 91, 4, 611-622.

Gercek, H. [2007] Poisson's ratio values for rocks. International Journal of Rock Mechanics and Mining Sciences, 44(1), 1-13.

Gray, D., P. Anderson, J. Logel, F. Delbecq, D. Schmidt and R. Schmid [2012] Estimation of stress and geomechanical properties using 3D seismic data. First Break, 30, 59-68.

Jarvie, D.M., R.J. Hill, T.E. Ruble and R.M. Pollastro [2007] Unconventional shale-gas systems: The Mississipian Barnett Shale of north-central Texas as one model for thermogenis shale-gas assessment. AAPG Bulletin, 91, 4, 475-499. 
Kupecz, J. A., \& Land, L. S. [1991] Late-stage dolomitization of the Lower Ordovician Ellenburger Group, west Texas. Journal of Sedimentary Research, 61(4).

Lebrun, D., V. Richard, D. Mace, and . Cuer [2001] SVD for multioffset linearized inversion: Resolution analysis in multicomponent acquisition. Geophysics, 66, 871-882.

Lucet, N., P.Y. Déquirez, and F. Cailly [2000] Well-to-seismic calibration: A multiwell analysis to extract one single wavelet, 70th Annual International Meeting, SEG Expanded Abstracts, 1615-1618.

Maxwell, S.C., C.K. Waltman, N.R. Warpinski, M.J. Mayerhofer, and N. Boroumand [2006] Imaging seismic deformation induced by hydraulic fracture complexity. SPE Annual Technical Conference and Exhibition.

Nivlet, P. [2004] Low-frequency constrain in a priori model building for stratigraphic inversion, SEG-74th Annual International Meeting, Expanded Abstracts, 1802-1805.

Owens, T. J., \& Zandt, G. [1997] Implications of crustal property variations for models of Tibetan plateau evolution. Nature, 387(6628), 37-43.

Perez, M. A., Gibson, R. L., \& Toksöz, M. N. [1999] Detection of fracture orientation using azimuthal variation of P-wave AVO responses. Geophysics, 64(4), 1253-1265.

Pollastro, R.M., D.M. Jarvie, R.J. Hill and C.W. Adams [2007] Geologic framework of the Mississipian Barnett Shale, Barnett-Paleozoic total petroleum system, Bend arch - Fort Worth Basin, Texas. AAPG Bulletin, 91, 4, 405-436.

Refunjol, X. E., Keranen, K. M., Le Calvez, J. H., \& Marfurt, K. J. [2012] Integration of hydraulically induced microseismic event locations with active seismic attributes: A North Texas Barnett Shale case study. Geophysics, 77(3), KS1-KS12.

Ribeiro, $N$ [2012] Joint inversion of multi-component seismic data for reservoir characterization of an offshore Campos Basin field, Brazil. First Break, 30, 87-91. 
Rickman, R., Mullen, M., Petre, J., Grieser, W., \& Kundert, D. [2008]. A practical use of shale petrophysics for stimulation design optimization: All shale plays are not clones of the Barnett Shale. In SPE Annual Technical Conference and Exhibition.

Rich, J.P. and Ammerman, M. [2010] Unconventional geophysics for unconventional plays. SPE Unconventional Gas Conference.

Roy, A., and K.J. Marfurt [2011] Cluster assisted 3D and 2D unsupervised seismic facies analysis, an example from the Barnett Shale Formation in the Fort Worth Basin, Texas. SEG 81th Annual International Meeting.

Rutledge, J.T. and Phillips, W.S. [2003] Hydraulic stimulation of natural fractures as revealed by induced microearthquakes, Carthage Cotton Valley gas field, east Texas. Geophysics, 68, 2, 441-452.

Sayers, C. M., \& Rickett, J. E. [1997] Azimuthal variation in AVO response for fractured gas sands. Geophysical Prospecting, 45(1), 165-182.

Shapiro, S.A. and Dinske, C. [2009] Fluid-induced seismicity: Pressure diffusion and hydraulic fracturing. Geophysical Prospecting, 57, 2, 1365-2478.

Shatilo, A. P., Bansal, R., Hefti, J., \& Rochette, C. [2012] Piceance 3C 3D Survey-Processing of Converted-wave Data in an Area with Azimuthal Anisotropy. In 74th EAGE Conference \& Exhibition.

Thompson, A., J. Rich, and M. Ammerman [2010] Fracture characterization through the use of azimuthally sectored attribute volumes. 80th Annual International Meeting, SEG Expanded Abstracts, 29, 1433-1437.

Walsh, J. B. [1965] The effect of cracks in rocks on Poisson's ratio. Journal of Geophysical Research, 70(20), 5249-5257. 
Zhang, K., B. Zhang, J. T. Kwiatkowski, and K. J. Marfurt [2010] Seismic azimuthal impedance anisotropy in the Barnett Shale. 80th Annual International Meeting, SEG Expanded Abstracts, 29, 273-277.

\section{Tables}

\begin{tabular}{|l|l|}
\hline Noise to Signal Ratio & $35 \%$ \\
\hline Uncertainties on IP $(\mathrm{g} / \mathrm{cm} 3 \mathrm{~m} / \mathrm{s})$ & 5000 \\
\hline Horizontal fitting length $(\mathrm{ft})$ & 1100 (10 intertraces) \\
\hline Constraints on IP $(\mathrm{g} / \mathrm{cm} 3 \mathrm{~m} / \mathrm{s})$ & $\begin{array}{l}\text { Low: } 9000 / 11000 \\
\text { High: } 18000 / 19000\end{array}$ \\
\hline $\begin{array}{l}\text { Frequency filtering for the low-frequency a priori } \\
\text { model }(\mathrm{Hz})\end{array}$ & $40 / 50$ \\
\hline Iterations & 20 \\
\hline
\end{tabular}

Table 1 - POSTSTACK INVERSION PARAMETERS

\begin{tabular}{|l|l|}
\hline Noise to Signal Ratio & $35 \%$ \\
\hline Uncertainties on IP $(\mathrm{g} / \mathrm{cm} 3 \mathrm{~m} / \mathrm{s})$ & 5000 \\
\hline Uncertainties on IS $(\mathrm{g} / \mathrm{cm} 3 \mathrm{~m} / \mathrm{s})$ & 1000 \\
\hline Uncertainties on density $(\mathrm{g} / \mathrm{cm} 3)$ & 0.5 \\
\hline Horizontal fitting length $(\mathrm{ft})$ & $1100(10$ intertraces $)$ \\
\hline Constraints on IP $(\mathrm{g} / \mathrm{cm} 3 \mathrm{~m} / \mathrm{s})$ & Low: $9000 / 11000$ \\
\hline Constraints on IS $(\mathrm{g} / \mathrm{cm} 3 \mathrm{~m} / \mathrm{s})$ & High: $18000 / 19000$ \\
\hline Constraints on density $(\mathrm{g} / \mathrm{cm} 3)$ & Low: $4500 / 5500$ \\
\hline Contraints on Poisson & High: $11000 / 12000$ \\
\hline Frequency filtering for the low-frequency a priori & Low: $2.1 / 2.3$ \\
model $(H z)$ & High: $2.9 / 3.1$ \\
\hline Iterations & Low: $0.02 / 0.05$ \\
\hline
\end{tabular}

Table 2 - PRESTACK INVERSION PARAMETERS 
Figures

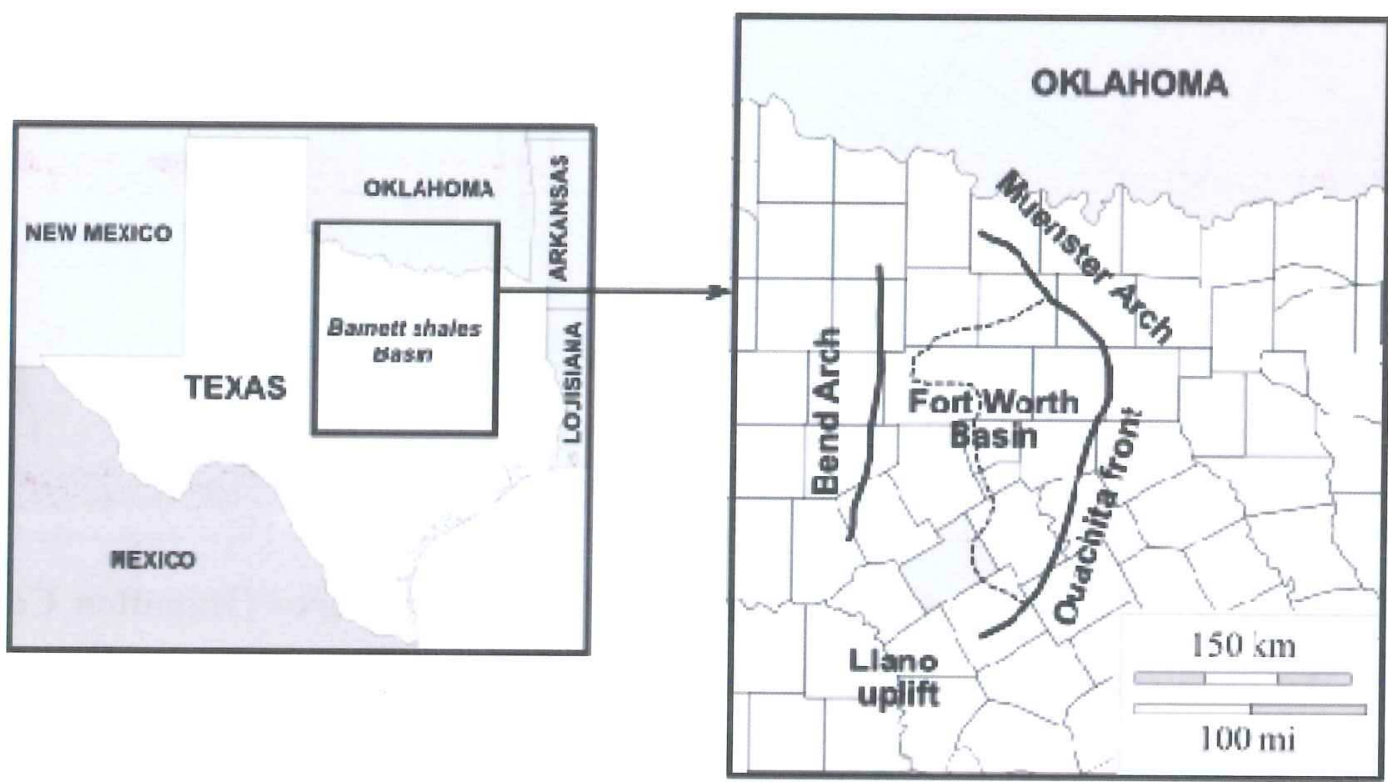

- Strt. . .Jral liprits

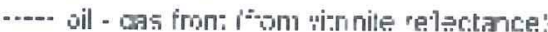

Figure 1 - Geographic extent of the Barnett Shale with major structural features and oil - gas front limit; inspired from [Pollastro et al., 2007].
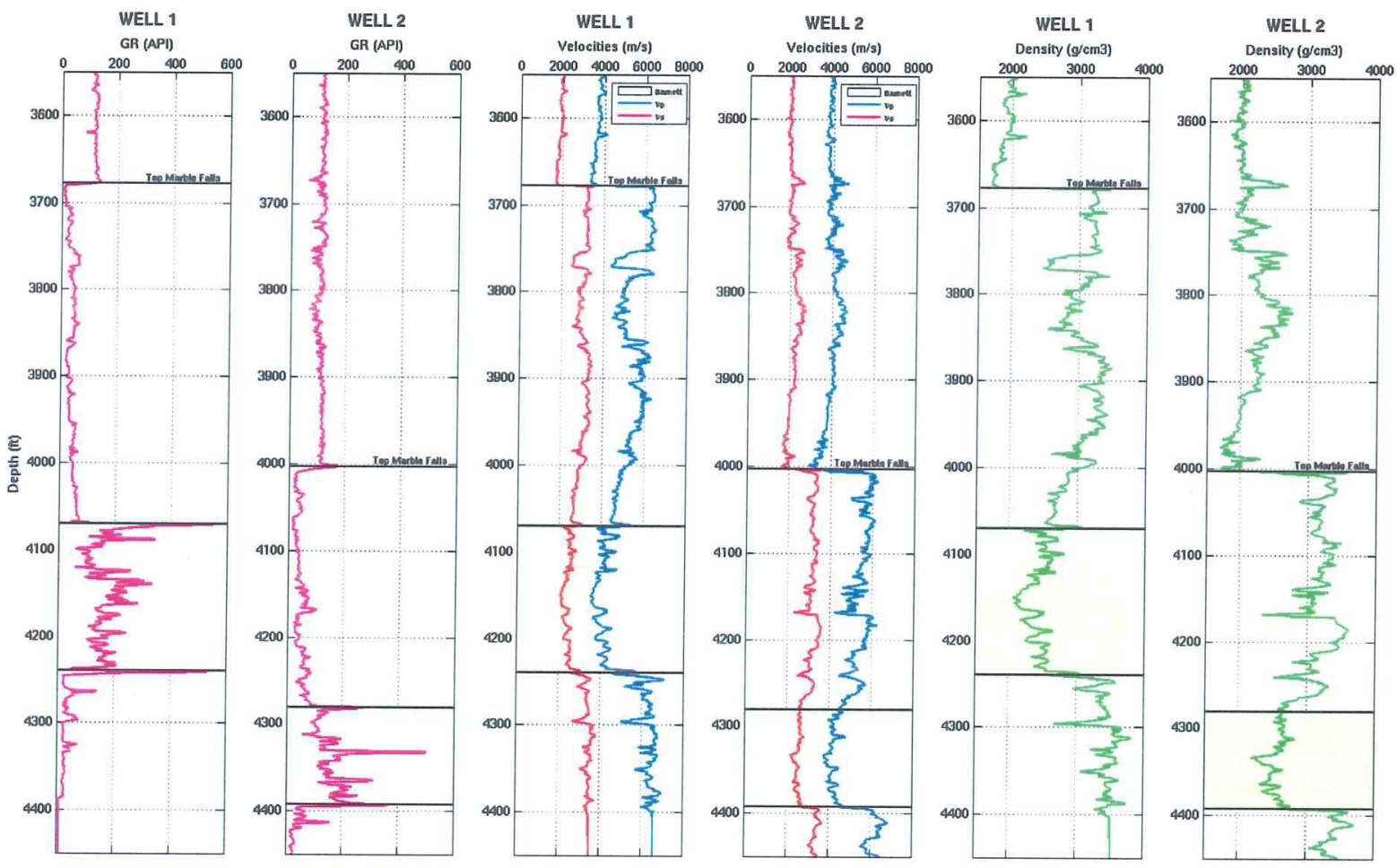

Figure 2 - Gamma ray, sonic and density logs for well 1 and well 2. The colored area corresponds to the Barnett Shales. 

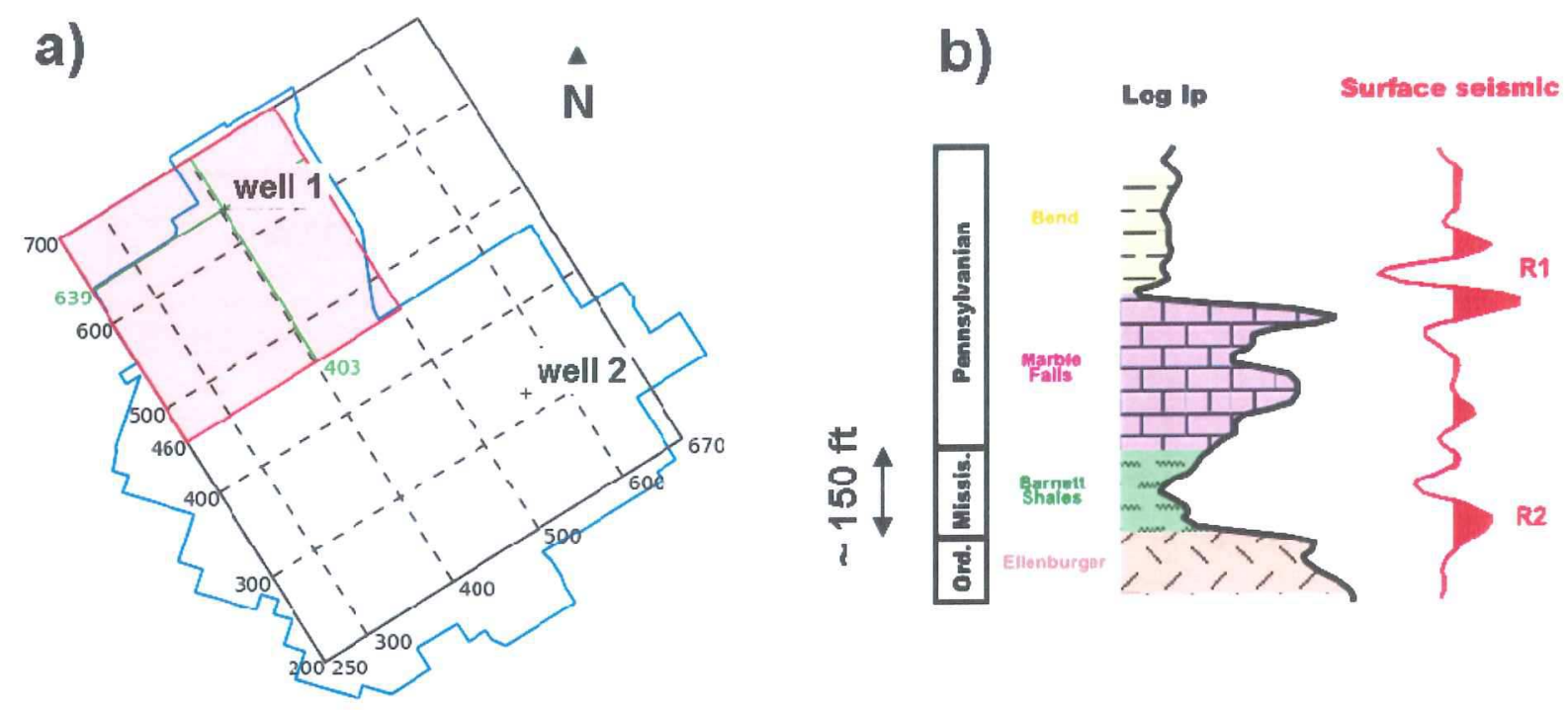

Figure 3 - a) Seismic survey design made on the investigated area (Hamilton County, Texas). We performed inversions only in the red area which is the most resolved. b) Stratigraphic log based on sonic and density logs compared with a seismic trace. Major reflectors are named R1 (top of Marble Falls) and R2 (top of Ellenburger). 


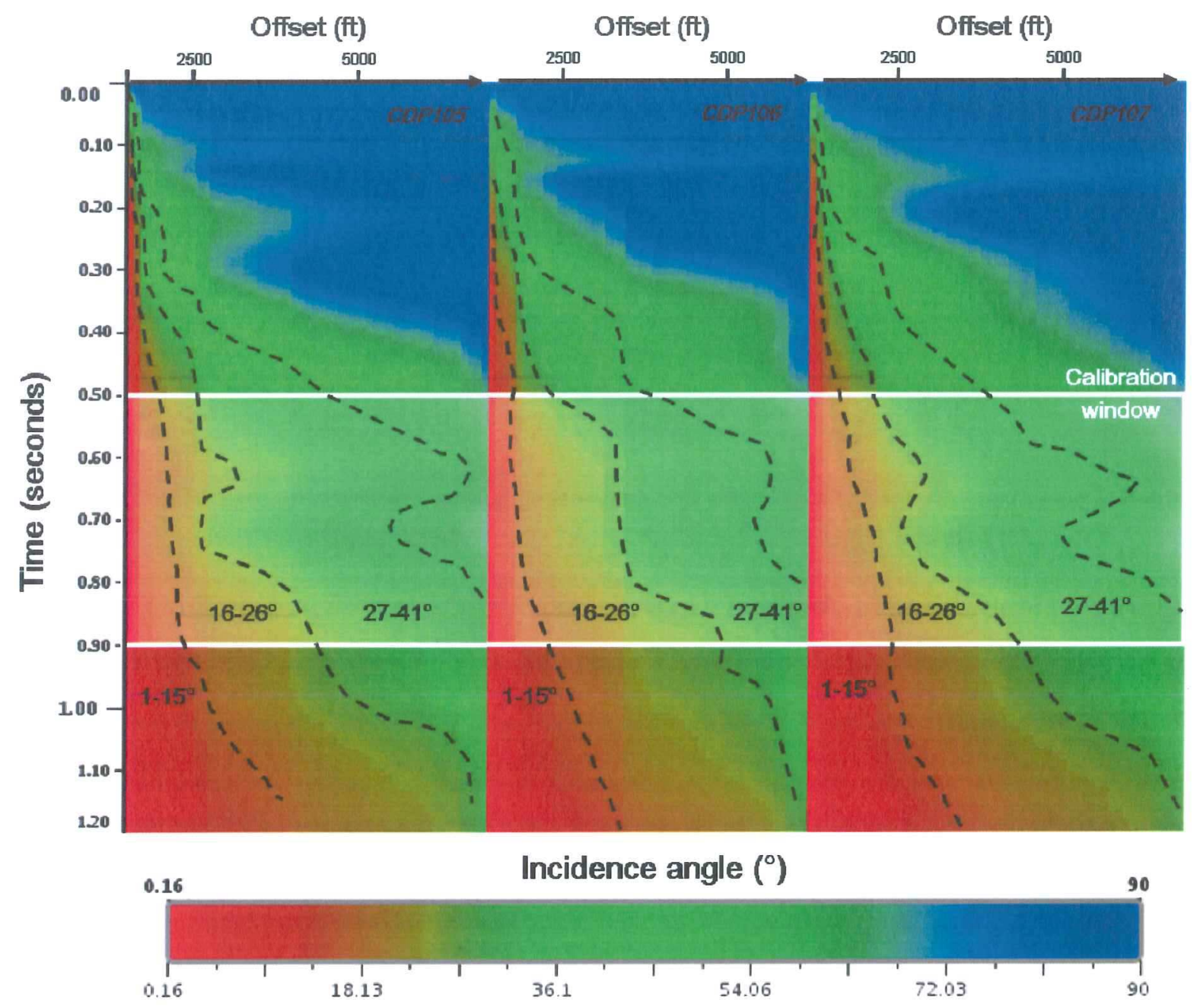

Figure 4 - Determination of the three sectors of incidence angles for 3 successive CDP migrated gathers: NEAR $\left(1-15^{\circ}\right)$, MID $\left(16-26^{\circ}\right)$ and FAR $\left(27-41^{\circ}\right)$. The white box corresponds to the calibration window used in the inversion process $(500-900 \mathrm{~ms})$. 

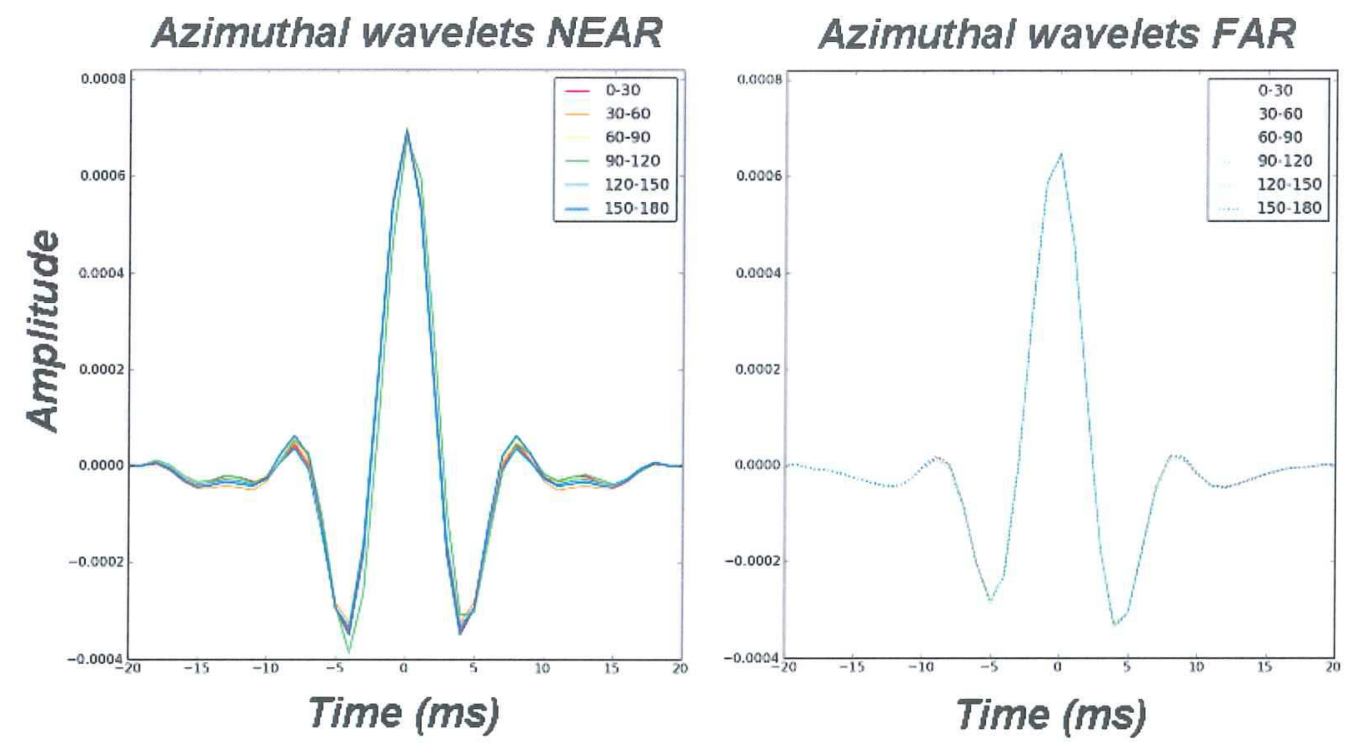

Figure 5 - Comparison of obtained wavelets (step 2 of the inversion workflow) from all 6 azimuthal sectors and only 2 incidence sectors called NEAR (left picture, corresponding to incidence angles between 1 and $15^{\circ}$ ) and FAR (right picture, corresponding to incidence angles between 26 and $45^{\circ}$ ). They are quite similar and we summarized their main characteristics: time shift between $[1.5 \mathrm{~ms}, 2.5 \mathrm{~ms}]$, phase shift between $\left[170^{\circ}\right.$, $180^{\circ}$ ] for the NEAR incidence and $190^{\circ}$ for the FAR incidence and energy coefficient normalization of $\sim 0.6$ for all of them.

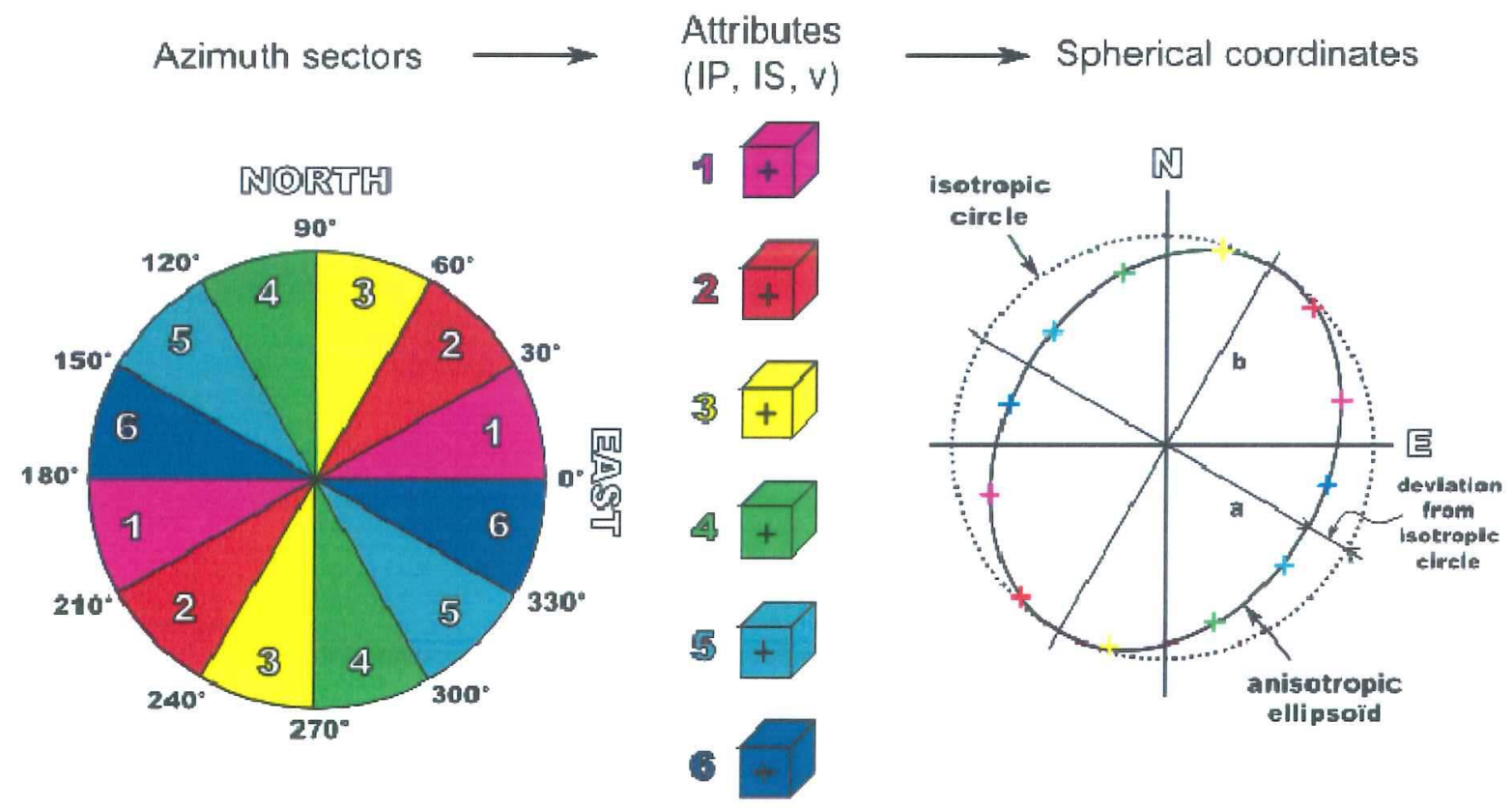

Figure 6 - Ellipse fitting principle applied on multi azimuth seismic attributes and derivatives (P-wave / S-wave impedances and Poisson's ratio). 


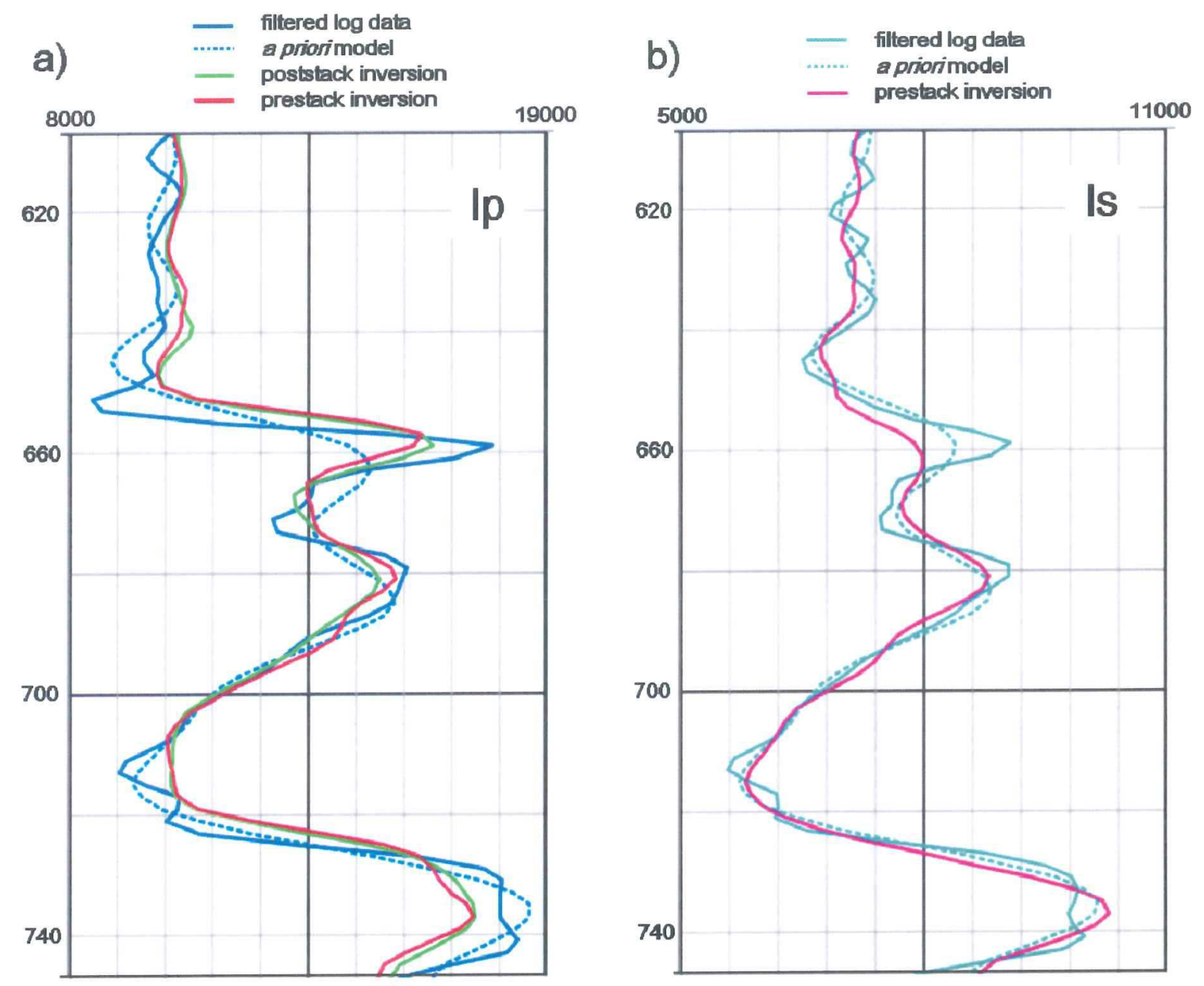

Figure 7 - Fitting at well 1: (a) log data, a priori model and inverted P-wave impedances. (b) log data, a priori model and inverted S-wave impedances. 

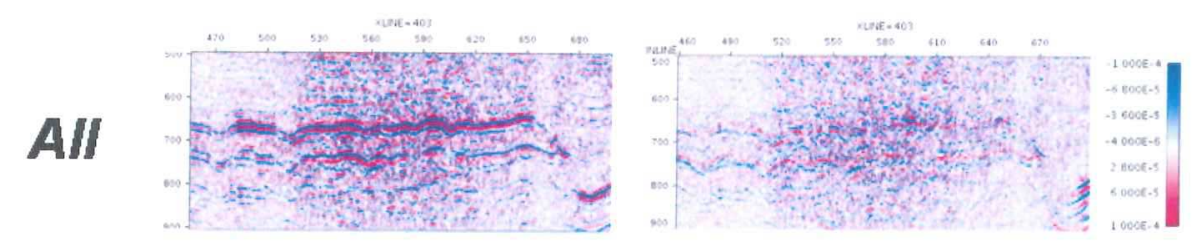

$15^{\circ}$
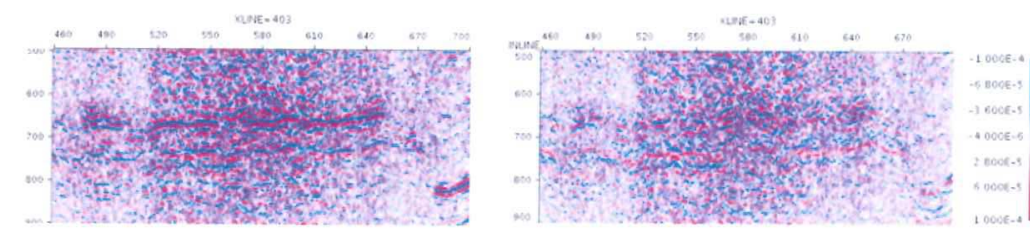

NEAR

$135^{\circ}$
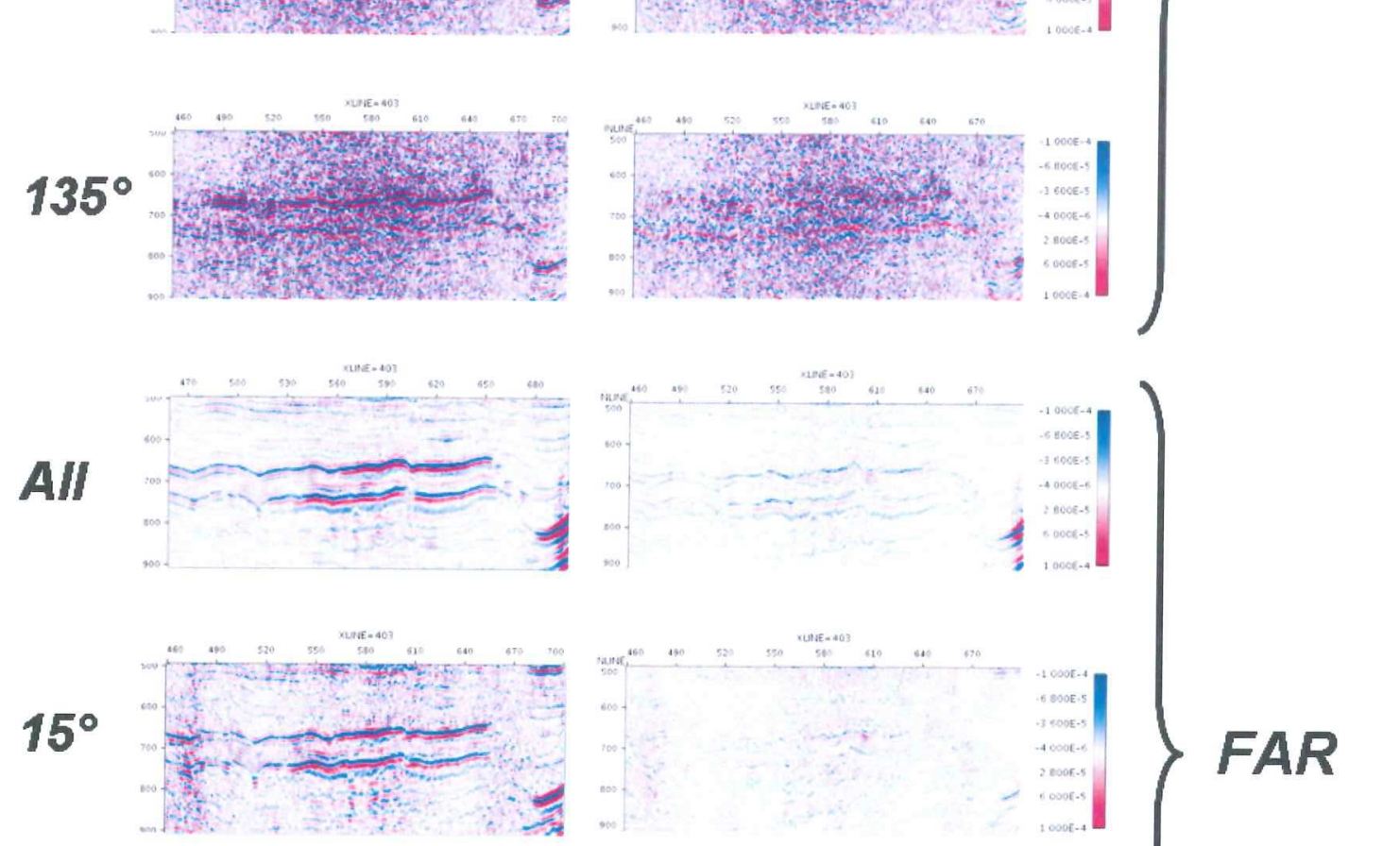

FAR

$135^{\circ}$
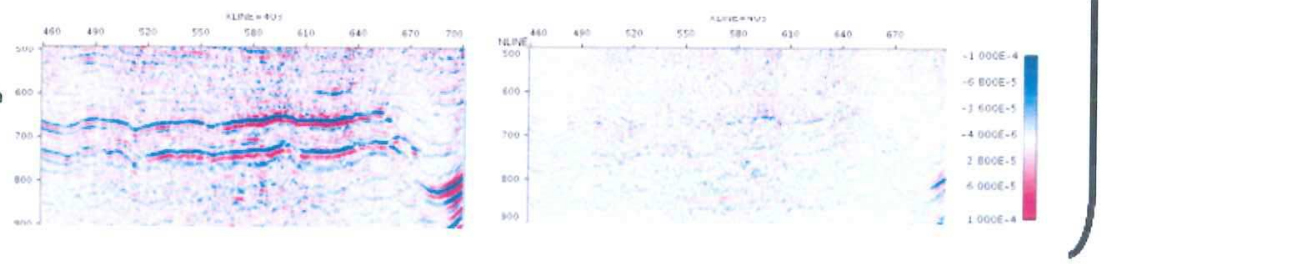

Figure 8 - Seismic data and residues, corresponding to the 2 incidence sectors NEAR and FAR. Residues are obtained with full pre-stack inversion (ALL) and for practical purposes we have only displayed 2 azimuthal sectors $\left(15^{\circ}\right.$ and $\left.135^{\circ}\right)$. The random distribution of these residues show the efficiency of the optimization process. NEAR residues are much higher than FAR ones due to the higher number of multiple reflections for this range of incidence angles. 

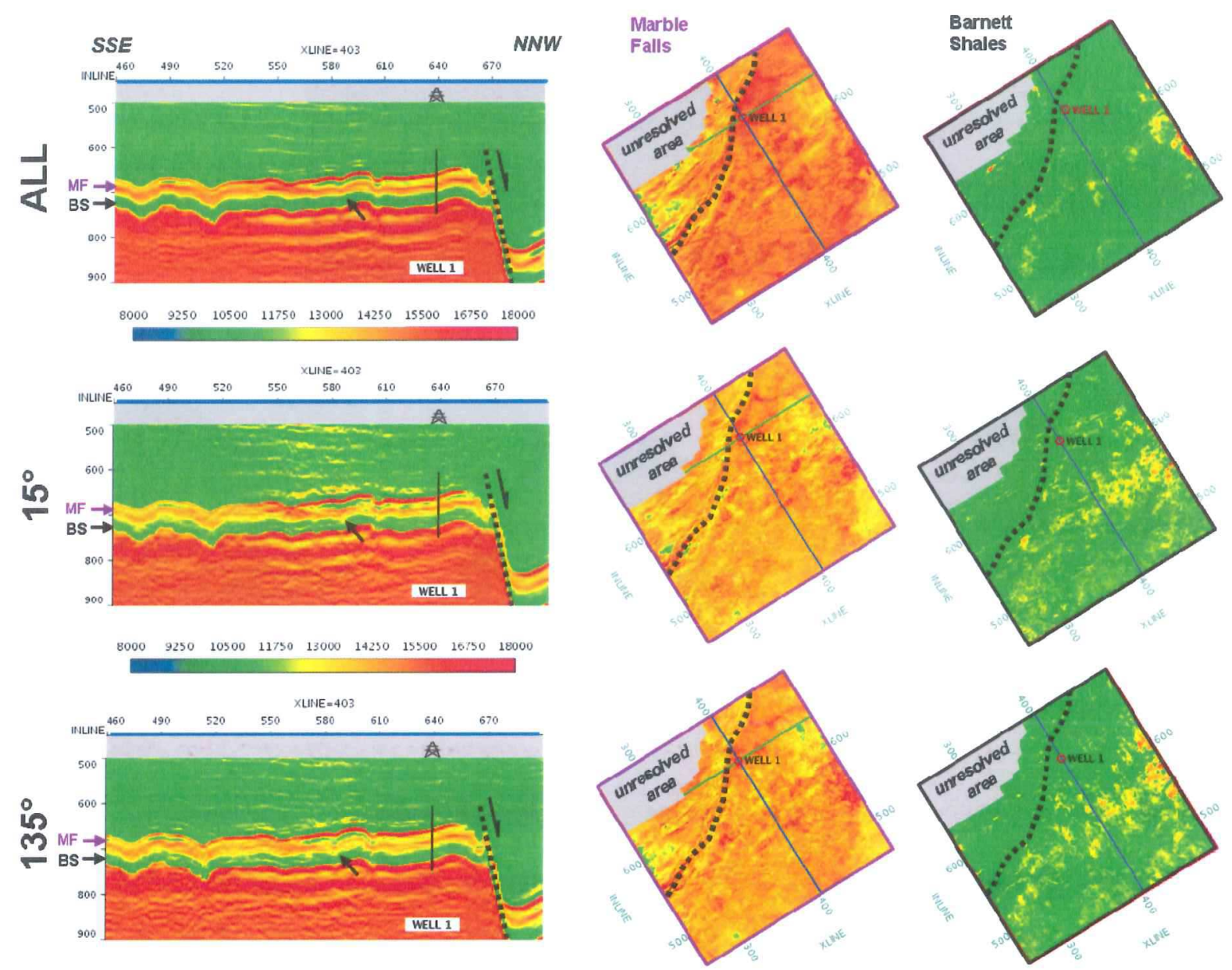

Figure 9 - Poststack inversion results: all azimuths (top), azimuth $1^{\circ}$ (middle) and azimuth $135^{\circ}$ (bottom). Left pictures represent the crossline 403 which one crosses well 1. Central and right pictures are horizon maps extracted through respectively Marble Falls (MF) and Barnett Shales (BS). Slices are built according geological horizons picked on the full azimuth seismic dataset. 

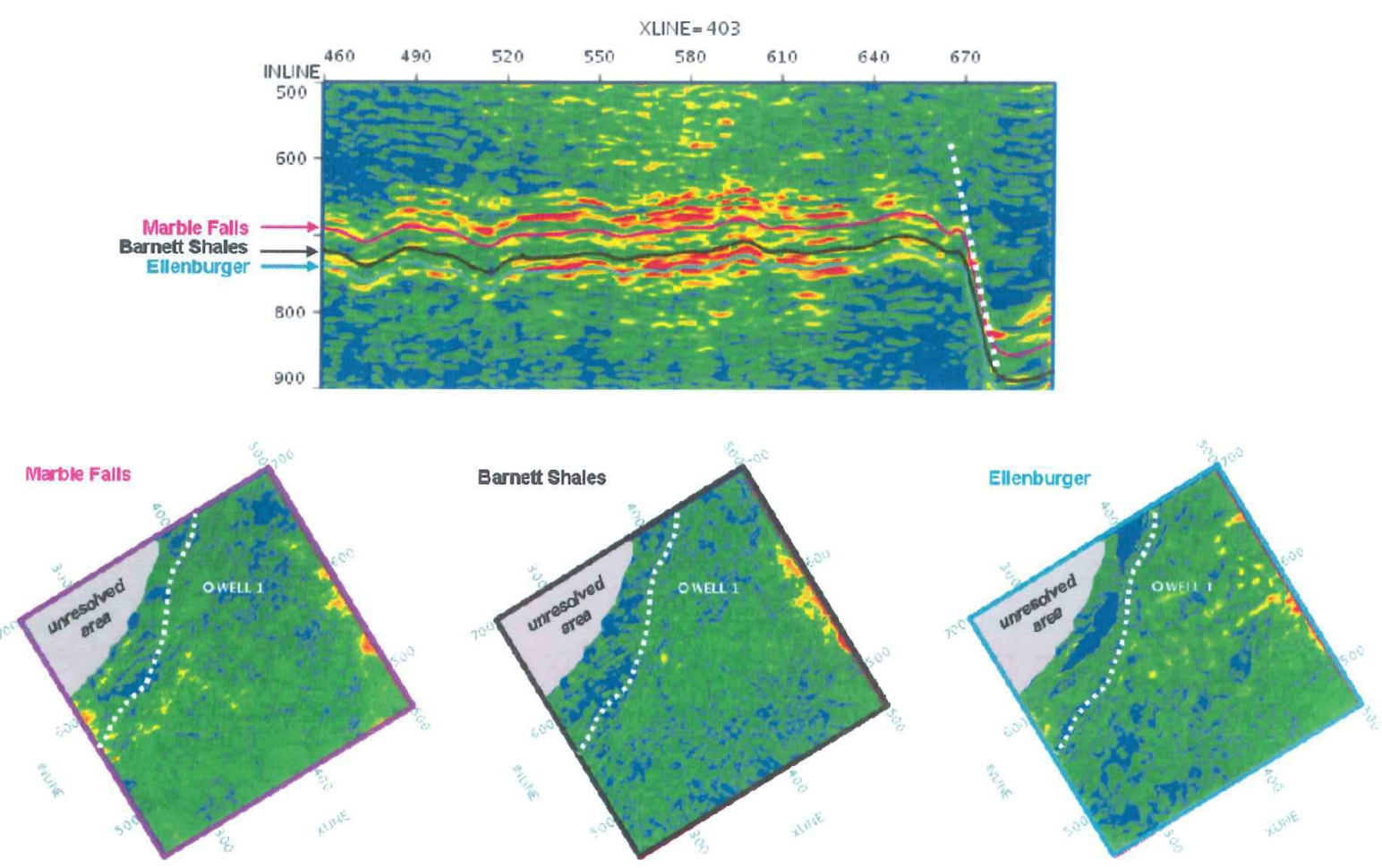

$\begin{array}{llllllllll}1.00 & 1.01 & 1.02 & 1.03 & 1.04 & 1.05 & 1.06 & 1.07 & 1.08\end{array}$

1.10

Figure 10 - IP anisotropic ratio inferred from multi azimuth poststack inversion results: crossline $\mathbf{4 0 3}$ and horizon maps extracted through three main geological layers (Marble Falls, Barnett Shales, Ellenburger).
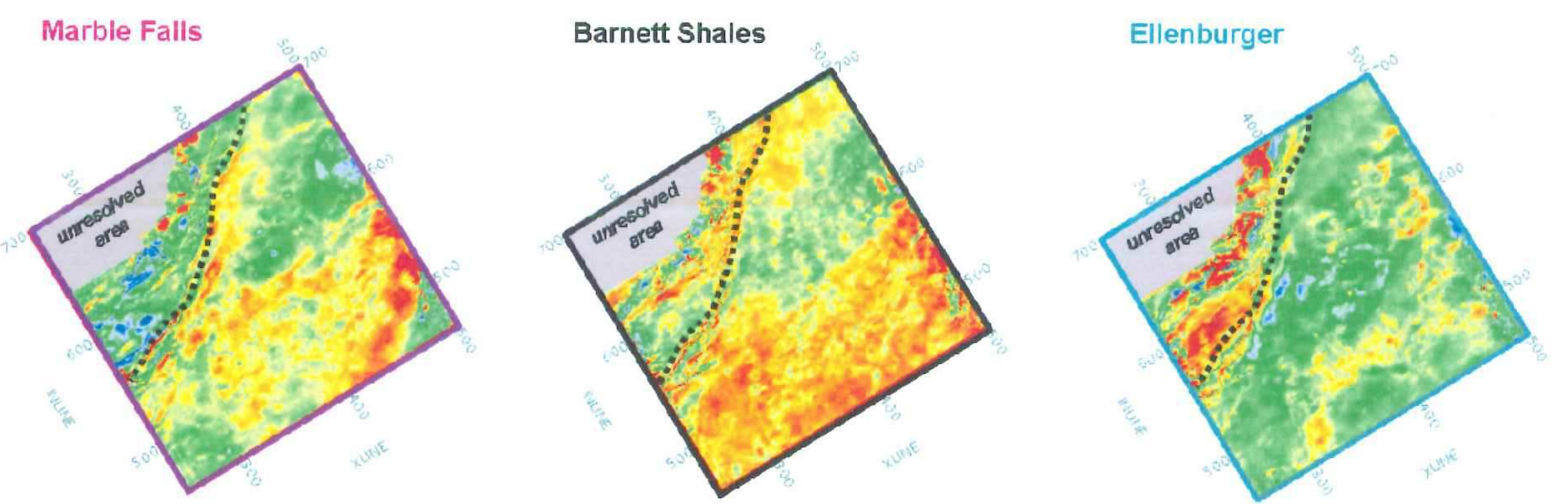

$\begin{array}{lllllll}0.000 & 0.046 & 0.093 & 0.139 & 0.186 & 0.232 & 0.279\end{array}$

0.350

Figure 11 - Poisson's ratio inferred from prestack results within the three main geological layers (horizon maps extracted through the volume). 

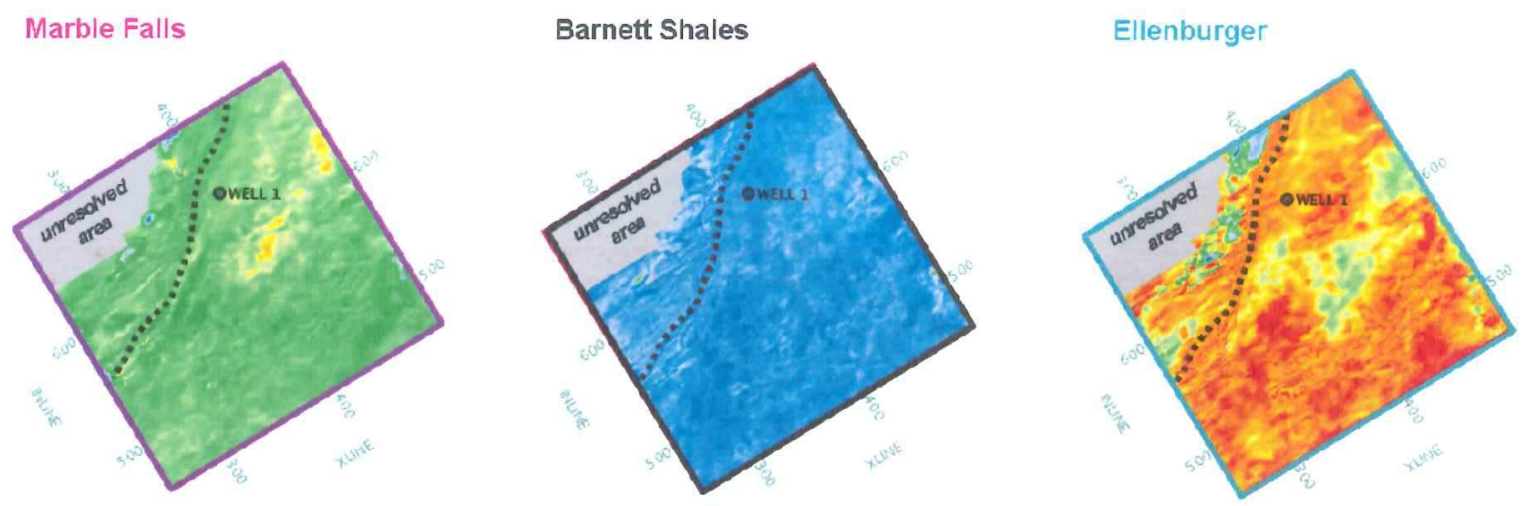

$20 \mathrm{GPa}$

$60 \mathrm{GPa}$ $100 \mathrm{GPa}$

Figure 12 - Young modulus inferred from prestack results within the three main geological layers (quite horizon maps extracted through the volume).

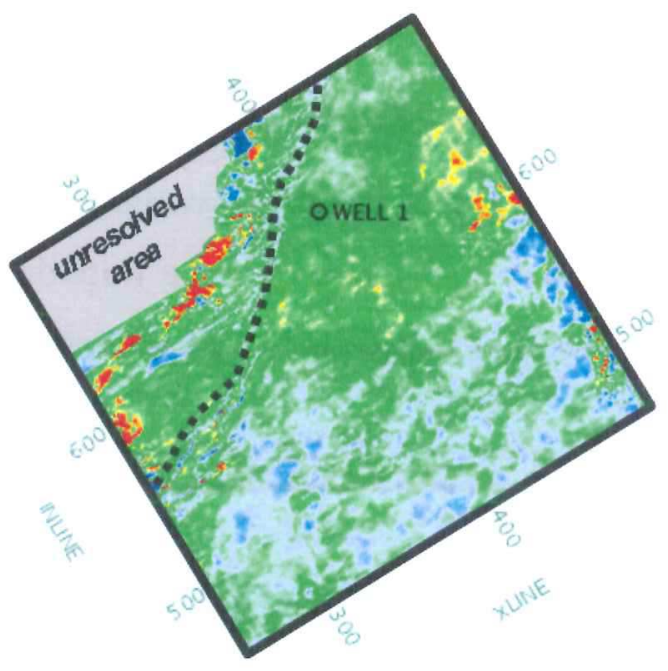

$20 \%$ $50 \%$ $80 \%$

Figure 13 - Brittleness inferred from prestack results within the Barnett Shales formation (quite horizontal slices built according geological horizons). 

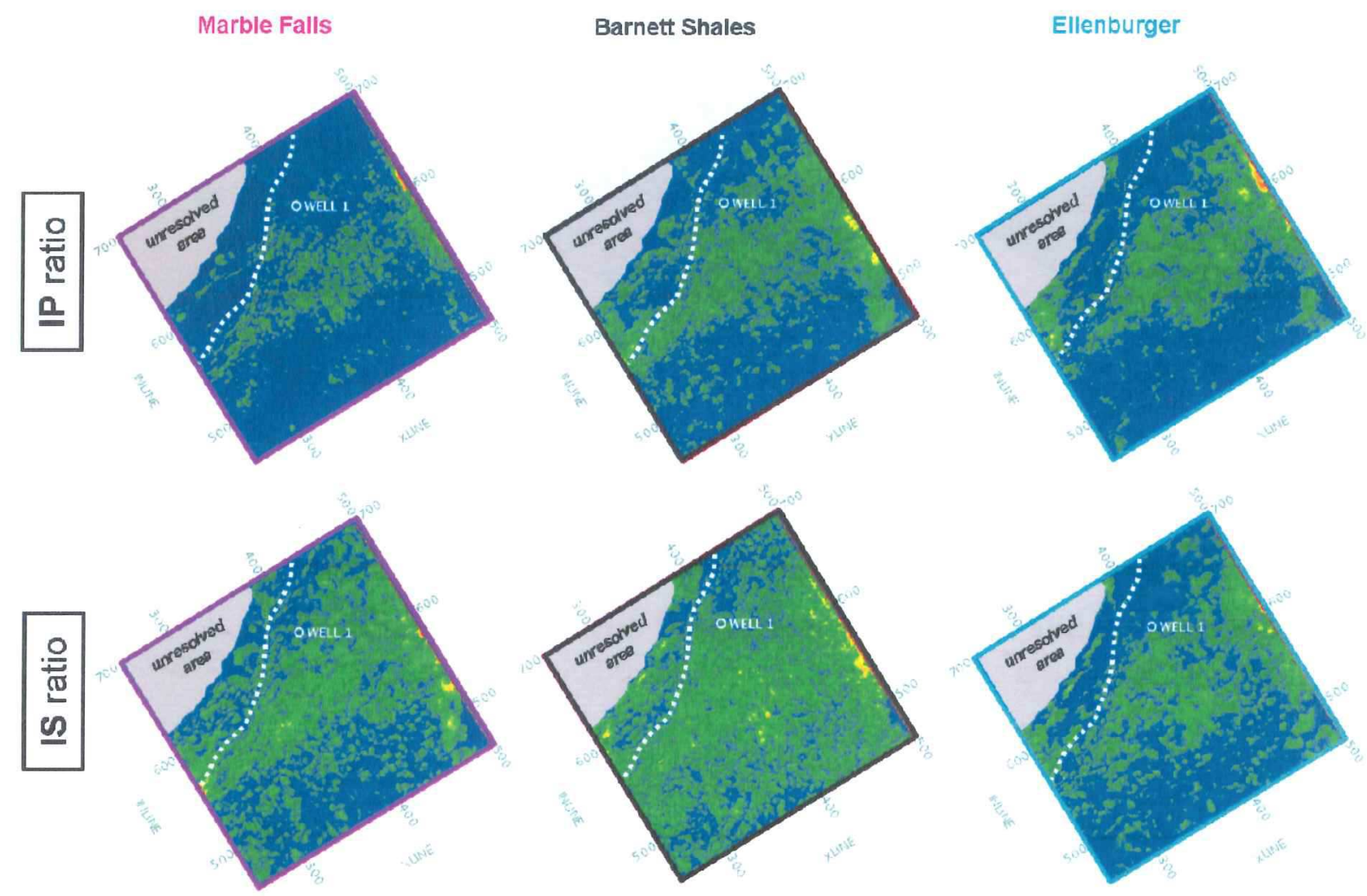

$\begin{array}{lllllllll}1.00 & 1.01 & 1.02 & 1.03 & 1.04 & 1.05 & 1.06 & 1.07 & 1.08\end{array}$

1.10

Figure 14 - Anisotropic ratios inferred from multi azimuth prestack inversion results: azimuthal anisotropy on $\mathrm{P}$-wave impedances (top) and S-wave impedances (bottom). Horizon maps extracted through three main geological layers (Marble Falls, Barnett Shales, Ellenburger). 

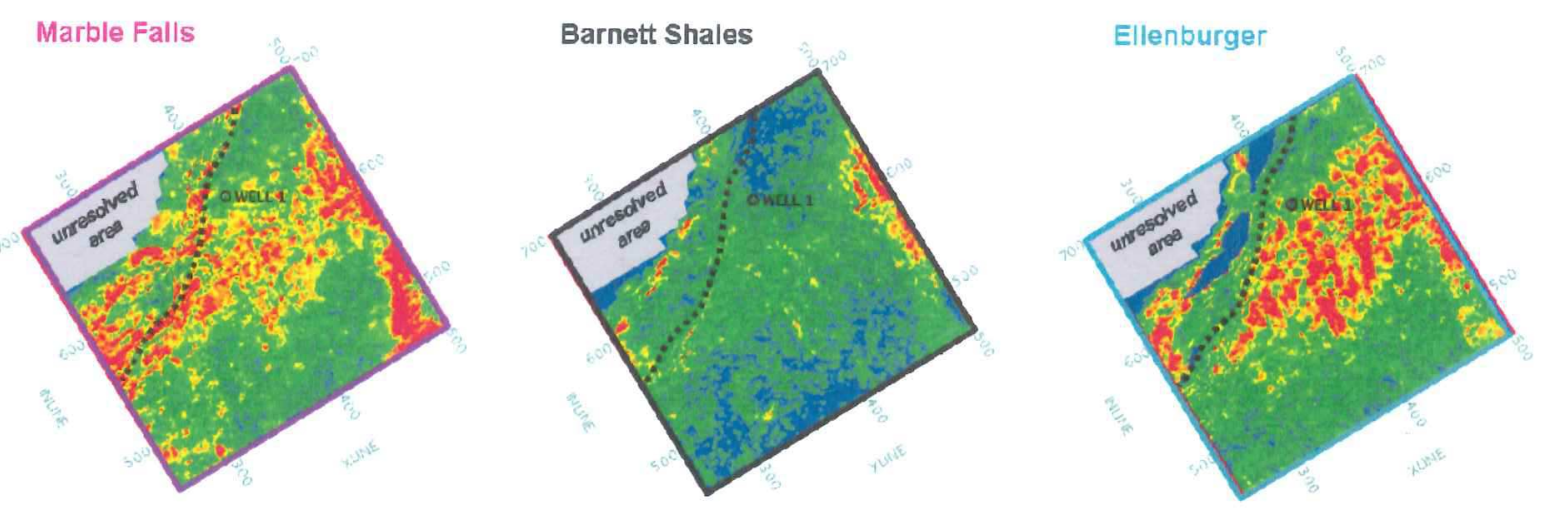

$\begin{array}{llllllllll}1.00 & 1.02 & 1.04 & 1.06 & 1.08 & 1.11 & 1.13 & 1.15 & 1.17 & 1.20\end{array}$

Figure 15 - Anisotropic ratio calculated on Poisson's ratio inferred from multi azimuth prestack inversion results. Horizon maps extracted through three main geological layers (Marble Falls, Barnett Shales, Ellenburger). 
